\title{
Microassembly of 3-D Microstructures Using a Compliant, Passive Microgripper
}

\author{
Nikolai Dechev, Member, IEEE, Student Member, ASME, William L. Cleghorn, and James K. Mills, Member, IEEE
}

\begin{abstract}
This paper describes a novel microassembly system that can be used to construct out-of-plane three-dimensional (3-D) microstructures. The system makes use of a surface-micromachined microgripper that is solder bonded to a robotic manipulator. The microgripper is able to grasp a micropart, remove it from the chip, reorient it about two independent axes, translate it along the $x, y$ and $z$ axes to a secondary location, and join it to another micropart. In this way, out-of-plane 3-D microstructures can be assembled from a set of initially planar and parallel surface micromachined microparts. The microgripper is $380 \times 410 \mu \mathrm{m}$ in size. It utilizes three geometric features for operation: 1) compliant beams to allow for deflection at the grasping tips; 2) self-tightening geometry during grasping; and 3) 3-D interlocking geometry to secure a micropart after the grasp. Each micropart has three geometric features built into its body. The first is the interlock interface feature that allows it to be grasped by the microgripper. The second is a tether feature that secures the micropart to the substrate, and breaks away after the microgripper has grasped the micropart. The third is the snap-lock feature, which is used to join the micropart to other microparts.

[1061]
\end{abstract}

Index Terms-Compliant, joint, microelectromechanical systems (MEMS), microgripper, microassembly, microstructure, micropart, snap-lock microjoint, three-dimensional (3-D).

\section{INTRODUCTION}

$\mathbf{M}$ ICROASSEMBLY refers to a process of manipulating components used to build a microsystem, from their original location of fabrication, to the final location of the assembly. It allows for the construction of complex microsystems which cannot be constructed using micromachining alone. It is necessary for applications such as the construction of out-of-plane microstructures, or microsystems requiring microparts that originate from two or more different chips or sources.

This paper describes a microassembly system which makes use of a surface micromachined microgripper, that is solder bonded to a robotic workstation. In order to complete one microassembly operation, the following steps are performed. The microgripper is used to grasp a surface micromachined micropart and remove it from the substrate of a chip. The micropart is then reoriented about two independent axes, and translated along the $x, y$ and $z$ axes to a secondary location. The micropart is then aligned with, and joined to another micropart

Manuscript received May 26, 2003; revised October 30, 2003. This work was supported in part by a Natural Sciences and Engineering Research Council of Canada (NSERC) equipment grant. Subject Editor C.-J. Kim.

The authors are with the Department of Mechanical and Industrial Engineering, University of Toronto, Toronto, ON M5S 3G8, Canada (e-mail: dechev@mie.utoronto.ca).

Digital Object Identifier 10.1109/JMEMS.2004.825311

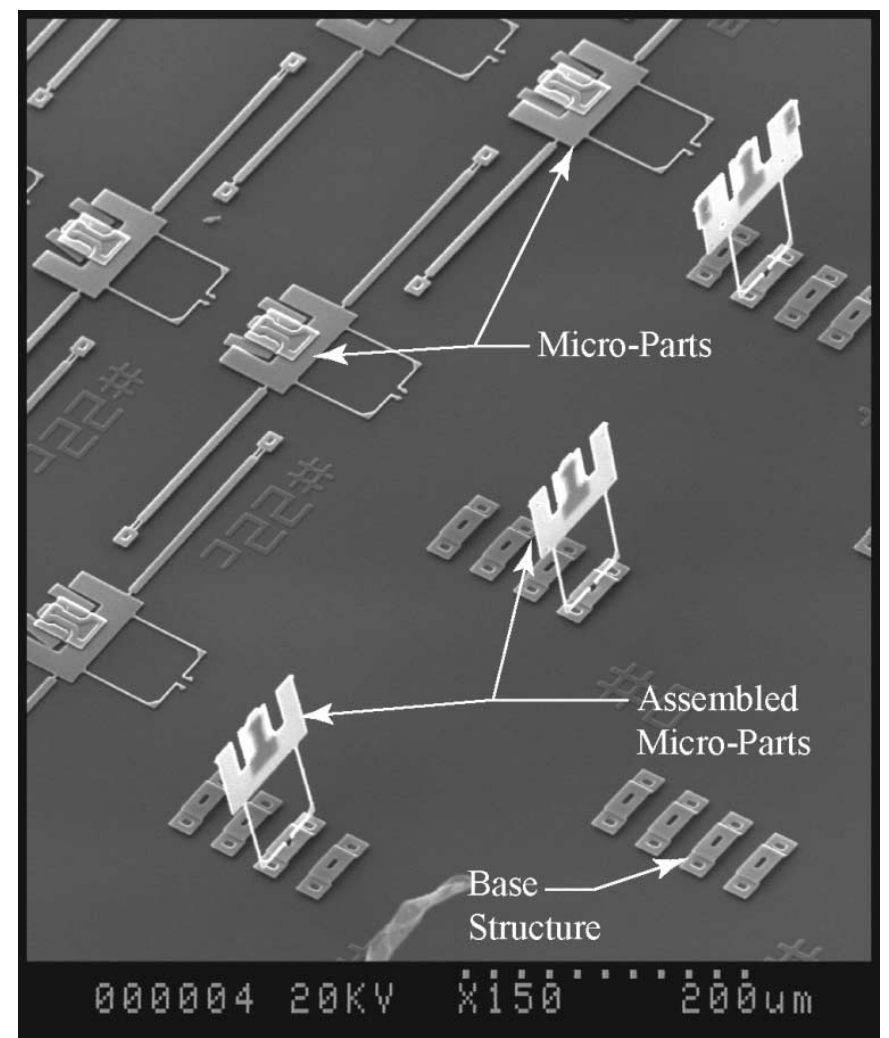

Fig. 1. Microparts tethered and joined to substrate.

at the secondary location. Last, the microgripper releases the micropart. Fig. 1 shows a scanning electron microscope (SEM) image of several "proof of concept" microparts, a few of which have been joined perpendicularly to other microparts (base structure) on the substrate.

Microassembly approaches can generally be categorized into two main groups, which are, parallel (batch) microassembly and serial (sequential) microassembly. Parallel microassembly systems perform the assembly process at multiple assembly sites simultaneously. One of the main parallel approaches is known as "flip-chip" or "batch transfer" microassembly [1], [2]. It can be used to fabricate planar, multilayer assemblies and can combine chips fabricated by different processes. Another common parallel microassembly approach involves "self-assembly" systems. The objective of this approach is to design an assembly system whereby constituent microparts will assemble themselves while under the influence of an external force. Self-assembly systems include polyimide joint technology [3] and solder self-assembly [4], which use heat to drive the self-assembly process, to create microstructures that fold out-of-plane. Plastic deformation magnetic assembly 
(PDMA) [5] uses strong magnetic fields to fold microstructures out-of-plane, and electrostatic force field microassembly [6] uses ultra-sonic vibration and electrostatic fields to sort and align microparts.

A number of microassembly approaches involve the use of "hinged" microparts that are folded out-of-plane [7]-[9], to create three-dimensional (3-D) microstructures. The hinges are built into the edges of the microparts, and are fastened to the substrate, or are fastened to other microparts. The microparts used in the folded assembly approach must necessarily be from the same chip, and further, must be located in adjacent positions (via the hinges) to the final assembly. Folded out-of-plane microassembly can be either a parallel or serial process.

Serial microassembly is a sequential process, in which assembly tasks are performed one after the other. To complete one assembly, a series of subtasks may be required, such as grasping microparts with various grasping tools, manipulation of microparts, and joining microparts. Serial microassembly has a lower assembly rate (number of assemblies performed per unit time) than parallel microassembly, however, it can be used to create microstructures that are more complex than parallel systems. This is due to the ability of serial microassembly systems to manipulate microobjects in 5 or 6 degrees of freedom (DOF).

Some examples of serial microassembly systems include orthogonal tweezers microassembly [10], where a robotic system using two steel probes is used to dexterously manipulate and join microparts. Another robotic-based serial system uses microtweezers to grasp microparts and insert them into slots [11]. Another system uses a microgripper to grasp microparts for insertion into slots [12].

All serial microassembly systems must make use of an appropriate end-effector to manipulate or grasp microparts. The most basic end-effector used for micromanipulation is the tungsten or steel probe. These probes can be used to push against microobjects to move them from one place to another, or to reorient them. To grasp microobjects, a commonly used end-effector is microtweezers. Microtweezers are fabricated using micromachining processes such as bulk micromachining of silicon crystal [13], [14], LIGA micromachining [15], or EDM (electrodischarge-machining) [11]. There are various designs of microtweezers with some designs more complex than others. Depending on the level of complexity, it is difficult to define a clear distinction between microtweezers and microgrippers. Generally, microtweezers can be considered as miniature versions of macrosized tweezers that grasp objects with two opposing tips that are flat and approximately parallel to each other. Microgrippers can be generally defined as devices that "interface" with microobjects using specially shaped grasping tips. The method of "interface" may consist of multiple contact points between the microobject and the microgripper, and may allow for multidegree-of-freedom restraint of the microobject. As such, microgrippers can be designed to grasp specific microobjects, to hold them more securely than they could be held by microtweezers or by a pair of probes. Examples of microgrippers include surface micromachined designs that are fabricated on chips, such that their tips can protrude over the edge of the chip [14], [16] to grasp objects.
Two observations can be made about end-effectors used for serial microassembly. First, (with the exception of a single probe) they are all actively controlled to open/close when grasping a micropart. In other words, the operator actively sends commands to the end-effector to close onto a micropart, or to open and release a micropart. Second, stiction forces (electrostatic, van der Waal's and surface tension forces) can make releasing a micropart from an end-effector, a difficult and unpredictable task. These observations will be discussed later, in relation to the microgripper presented here.

Section II describes the methodology of this microassembly process. Section III describes the robotic workstation. Section IV describes the design of the compliant microgripper. Section V describes the microparts. Section VI discusses the microassembly system.

\section{Methodology of the Microassembly Process}

\section{A. Purpose of the Microassembly System}

The purpose of this work is the development a general microassembly system. This system is used to create joints between microparts that can be in-plane or out-of-plane with respect to the substrate. The system can accommodate microparts of different shapes, microparts fabricated from different materials, and can combine microparts from multiple chips, to assemble a single microstructure.

\section{B. Microassembly Concept}

The microassembly performed by this work is serial, or "sequential", as one micropart is handled at a time. In order to maximize the assembly rate, this system has been designed such that the assembly procedures can be automated. As such, several assumptions have been made. 1) microparts are of known standard sizes and geometries. 2) Microparts can have their design altered slightly to accommodate the microassembly system. 3) Conventional robotic assembly systems use components that are prearranged in trays or on feed tapes. Therefore, it would follow that the microparts are arranged in ordered, specific locations on the substrate, to speed the grasping process. 4) Microassembly implies that microparts would be joined in some way to other microparts, and not released freely into the environment.

Based upon assumptions 1)-4), it is proposed that each micropart used by this system, must be designed in such a way that it incorporates three modular features. These modular features are based on geometrical shapes, and can be adapted to a variety of microparts. They are: a) an interface feature, that allows the micropart to be grasped by the microgripper; b) a tether feature, that secures the micropart to the substrate, and breaks away after the microgripper has grasped the micropart; and c) a snap-lock feature, which is used to join the micropart to other microparts.

In order to grasp and manipulate the microparts, a compliant, passive microgripper is proposed. It is fabricated by surface micromachining and has been specifically designed to grasp the interface feature incorporated into each micropart. When developing the microgripper, it was noted that a "passive" design could be used to accomplish the grasping and releasing operations of microparts associated with this microassembly concept. 
A "passive" design refers to the fact that there is no active control of the gripper tips to open or close. Instead, the gripper tips passively open, as the microgripper is inserted into the mating interface feature of a micropart. Similarly, the gripper tips passively open to release a micropart, after that micropart is joined to another. The design of the microgripper is described in Section IV.

\section{Overview of the Microassembly Procedure}

The first step of the microassembly procedure, is to bond a microgripper to the robotic workstation. A device named the "contact head" [17] was developed to bond directly to the microgripper. Fig. 2(a) illustrates a diagram of the distal arm of the workstation, which holds the contact head. The workstation is shown in Fig. 3. Note that the elements shown in Fig. 2 are not to scale. The contact head is a custom designed soldering iron that solders itself to a microgripper. In doing so, the contact head acts as an interface between the macro-sized workstation and the micro-sized microgripper ( $380 \mu \mathrm{m}$ wide by $410 \mu \mathrm{m}$ long). Solder bonding allows the contact head to be electrically and mechanically joined to the microgripper. In addition, should the microgripper become damaged, the solder is remelted, the old microgripper is brushed away, and a new microgripper is solder bonded.

The contact head shown in Fig. 2(a), is oriented $45^{\circ}$ below the horizontal. In this orientation, the "metal tip" on the contact head is the lowest point of the distal arm assembly. This orientation allows the metal tip to make contact with the microgripper and ensures that the macro-sized elements of the distal arm, do not interfere with the chip substrate due to their relatively large size. This orientation also allows the metal tip to be in direct view of the video microscope system, which must have the optical objective $20 \mathrm{~mm}$ directly above the metal tip. Details of the contact head design and the automated solder bonding procedure are described in [17].

The microgripper is attached to the chip substrate by tethers, as shown in Fig. 2(a) and Fig. 4. The tethers are attached to anchor pads, which are permanently attached to the substrate. The tethers are designed to be strong enough to hold the microgripper onto the substrate during transportation of the chips. They also immobilize the microgripper during the solder bonding operation.

The solder bonding operation consists of the following process. Tin-lead solder is applied to the heated metal tip of the contact head, and melts. While the solder remains molten, the metal tip is aligned with the solder pad of the microgripper, and pressed down against it. The metal tip is then allowed to cool. During the cooling phase the solder solidifies, causing the tethers to break away, thereby freeing the microgripper from the substrate. After a completed solder bonding operation, the distal arm is commanded up along the $z$-axis, as shown by the dashed arrows of Fig. 2(a). A video movie of a typical solder bonding operation is available online at [18]. The microgripper is now ready to be used for grasping operations. Fig. 5 shows an SEM image of the microgripper solder bonded to the metal tip of the contact head.

After soldering a microgripper to the metal tip, the microgripper becomes the lowest point of the distal arm, as illustrated

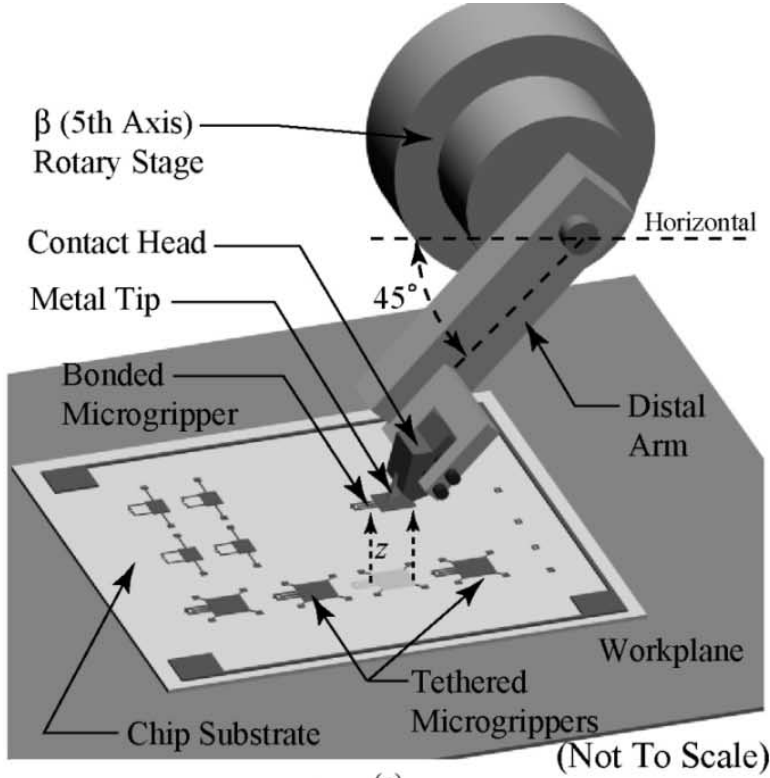

(a)

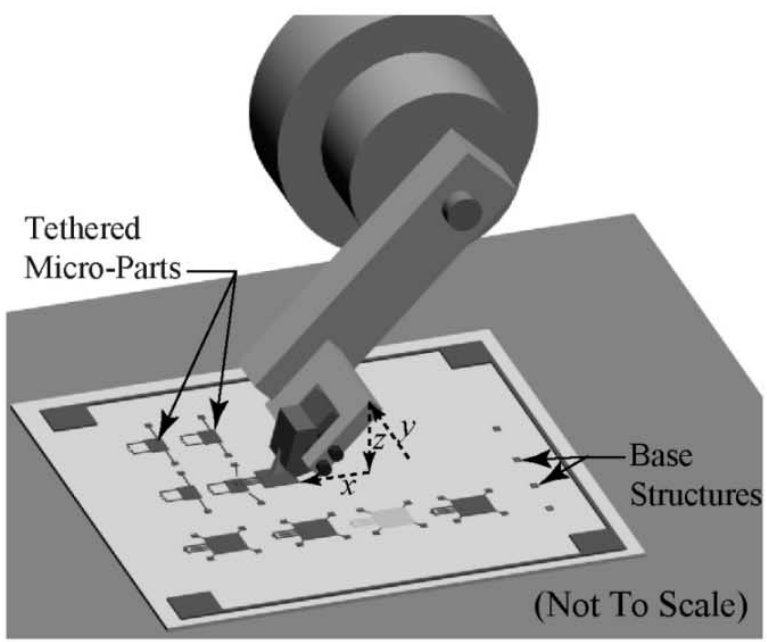

(b)

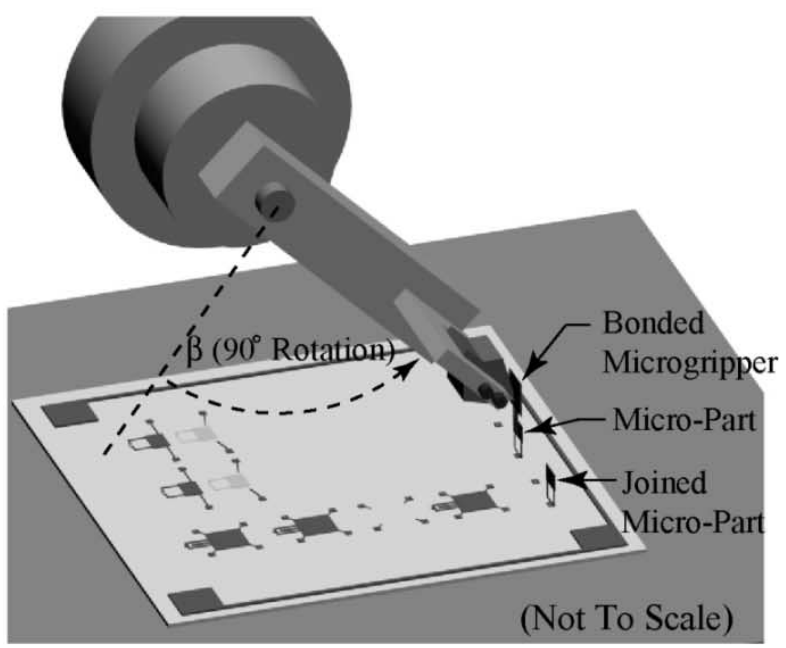

(c)

Fig. 2. Illustration of solder bonding, grasping and joining orientations of the distal arm assembly. (a) Distal arm in soldering orientation; (b) compliant microgripper in grasping orientation; and (c) compliant microgripper in joining orientation.

in Fig. 2(b). The microgripper is translated along the $x, y$ and $z$ axes to align the gripper tips with the interface feature of a 


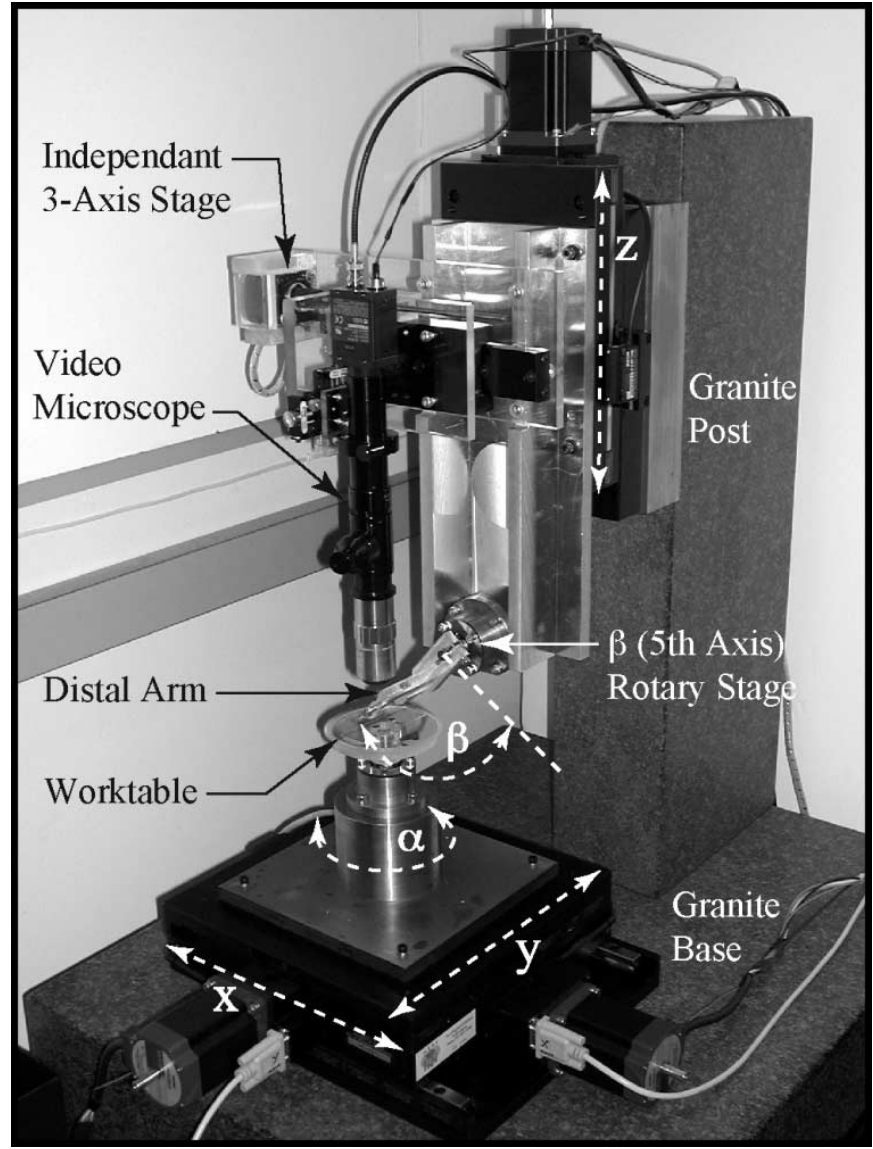

Fig. 3. Manipulator and joiner of microparts (MJMP).

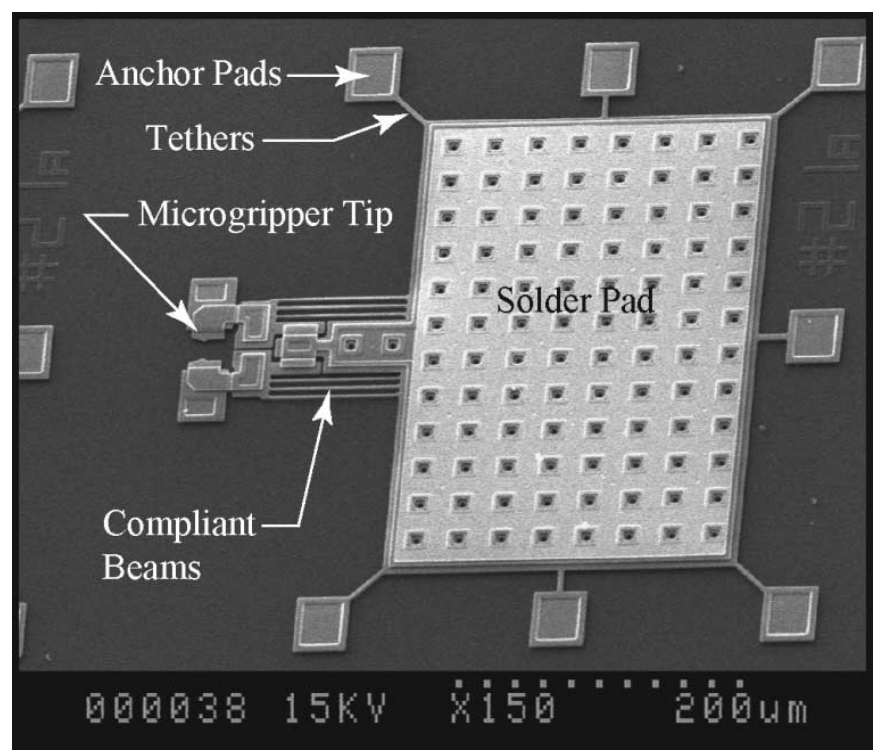

Fig. 4. SEM image of compliant microgripper.

micropart. Next, the microgripper grasps the micropart, which is described in Section IV-B.

Each micropart is tethered to the substrate, as illustrated in Fig. 2(b). After a successful grasp, the microgripper must remove the micropart from the substrate. In order to do this, the microgripper is commanded further in the $x$-direction, which causes the tethers to break away from the micropart, in a pre-

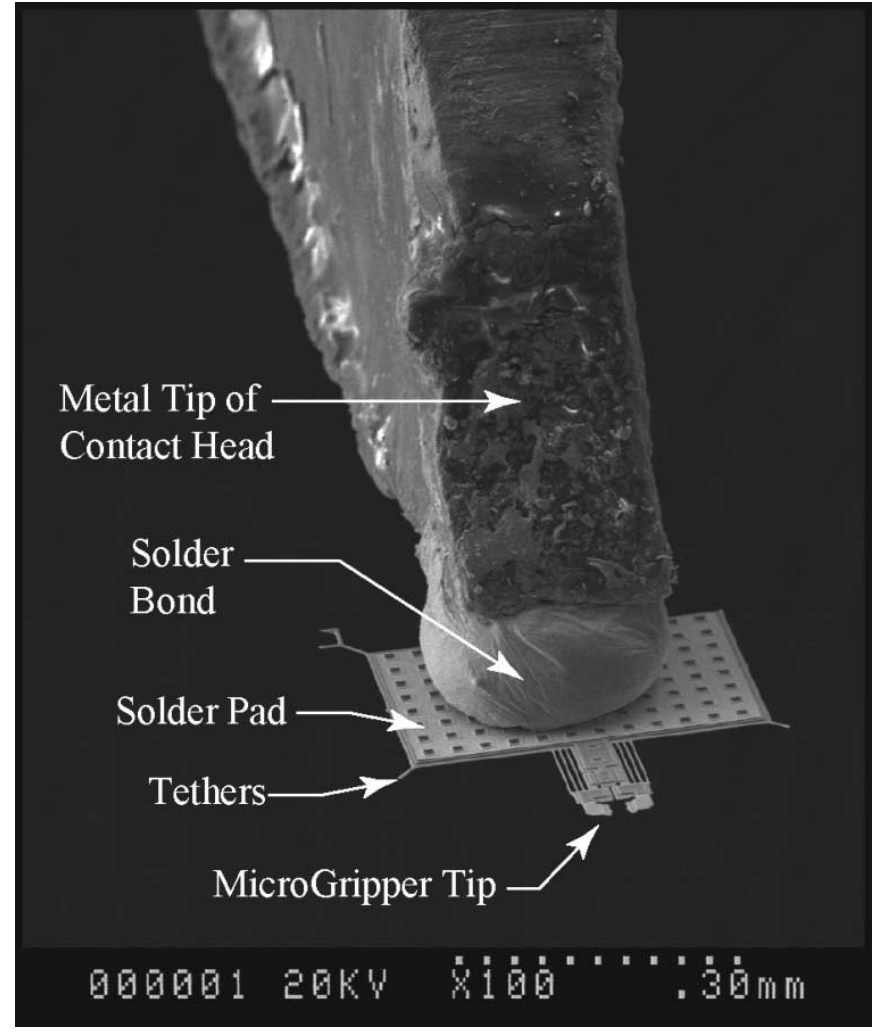

Fig. 5. Microgripper solder bonded to metal tip.

dictable manner. The micropart tether design is described in Section V-B.

After a grasping a micropart and breaking the tethers that hold it, the micropart is free from the substrate. In order to join the micropart perpendicularly to the substrate, the distal arm is rotated $90^{\circ}$ counterclockwise about the $\beta$ axis, as shown in Fig. 2(c). Note that in this orientation, the contact head is again $45^{\circ}$ below the horizontal, although the microgripper and the micropart are now perpendicular to the substrate. Also, note that the microgripper is again the lowest point on the distal arm. In this orientation, the microgripper is able join the micropart that it is grasping, to the base structure microparts on the substrate, using a snap-lock joint. The snap-lock joining operation is described in Section V-C.

\section{ROBOTIC WORKSTATION DESIGN}

\section{A. Mechanical Design}

A five-axis robotic manipulator, named the Manipulator and Joiner of Micro Parts (MJMP), shown in Fig. 3, is the basis of the microassembly system. Its axes are split into two groups with the $x, y$ and $\alpha$ axes mounted on a granite base, and the $z$ and $\beta$ axes mounted on a granite post. This split configuration was chosen since it eliminates interference problems [19] between the macro-sized elements of the MJMP and the microsized components on the chip substrate.

The $x, y$ and $z$ axes are comprised of Danaher Precision Systems Ltd. crossed-roller bearing stages, driven by ball-bearing lead screws with a $2 \mathrm{~mm}$ lead. The $x$ and $y$ stages have a travel of $200 \mathrm{~mm}$ each, and the $z$ stage has a travel of $150 \mathrm{~mm}$. Oriental Motor, Vexta five-phase stepper motors are used to drive the 
three translation stages and are set to 4000 steps per revolution, which provides a linear step distance of $0.5 \mu \mathrm{m}$. The translation stages are equipped with linear encoders with a $0.1 \mu \mathrm{m}$ resolution. The repeatability of the translation stages is $+/-0.1 \mu \mathrm{m}$. The $\alpha$ and $\beta$ rotational axes are custom designed to have radial and axial runouts of less than $2 \mu \mathrm{m}$. This is achieved by the use of NSK-RHP P2 precision angular contact ball bearings. The MJMP is able to manipulate microparts by $360^{\circ}$ about the $\alpha$ axis, and $+/-50^{\circ}$ (from the vertical) about the $\beta$ axis. The motors that drive the rotational axes have a step resolution of $0.36^{\circ}$. A 5-axis Galil motion control card, interfaced to a personal computer, controls the three translation axes and two rotation axes.

The MJMP is designed for control in a dual mode manner. In one mode, it is designed as a tele-robotic system that is controlled by a human operator. In the other mode, it is designed for automatic control using sensor feedback, in order to maximize the assembly rate. This dual approach is pragmatic for this system. Due to the experimental nature of grasping, manipulating and joining microparts, human operator control is a prerequisite to fully defining a particular microassembly process and its parameters. Work involving experimental procedures such as grasping and joining is carried out by an operator using a joystick. The operator relies on the video microscopy system for visual feedback, and a readout display showing the linear encoder positions. For proven procedures, such as the locating the plane of the substrate chip, and solder bonding to microgrippers, the MJMP uses automatic control [17], via a program and data capture through the Galil card. Automatic control of the grasping and joining operations is the ultimate goal of this system, and would require image processing of the video image, and visual servoing [20] for implementation. In particular, image processing is required for the task of localizing the micropart with respect to the microgripper prior to a grasping operation or localizing the snap-lock tips of a micropart with respect to the target joint site, prior to a joining operation.

\section{B. Video Microscope System}

The video microscope system consists of an Infinitube In-Line assembly, a Mitutoyo M Plan Apo 20X objective and a Sony XC-ST50 monochrome CCD camera. The field of view of the video image is $320 \times 240 \mu \mathrm{m}$, the resolution is $0.7 \mu \mathrm{m}$, and the depth of focus is $1.5 \mu \mathrm{m}$. The microscope system is mounted on an automated three-axis translation stage, which is mounted onto the $z$-axis of the MJMP. This allows it to be moved independently of the MJMP, in the $x, y$ and $z$ axes using automatic control or operator control via a joystick. The microscope is able to view the metal tip (and any microgripper bonded to it), in the orientation shown in Fig. 2(a) or Fig. 2(c) which allows the operator to view the bonding, grasping or joining operations.

\section{PASsive, COMPLiAnt MicrogripPER DESIGN}

The purpose of the microgripper, is to facilitate the assembly of the microparts. It is required to perform four functions, which are: a) securely grasp the microparts, b) remove the microparts from the substrate by breaking the tethers, c) join the microparts to other microparts, and d) release the microparts. The microgripper is fabricated using the MUMPs [21] process, and is designed to handle the deflections and the resulting stresses that occur while performing these four functions.

The microgripper performs these functions by the use of three main design features. First, the microgripper has compliant beams that allow the gripper tips to translate, as the tips are inserted into a micropart. Second, the microgripper has a self-tightening grasp that arises when it removes a micropart from the substrate. This allows the microgripper to grasp a micropart with a force proportional to the removal force. Third, the gripper tips have a 3-D interlocking geometry that secures microparts in 6 DOF after they are grasped.

\section{A. Microgripper Design}

The microgripper design is based on deflection and stress analysis. The microgripper is designed to undergo different deflections, while it performs the four functions of micropart grasping, removal, joining and release. This approach was used since the grasping forces cannot be directly measured, however, the deflections can be observed and measured. In addition, it is known that Young's modulus for polysilicon is approximately $160 \mathrm{GPa}$ [22], [23] and the ultimate stress is approximately 2 $\mathrm{GPa}$ [22], [23]. Given these values, the microgripper geometry is designed such that during operation, its internal stresses will not exceed $25 \%$ of the ultimate stress of polysilicon.

Proposed microgripper designs were modeled using software. The designs were first drawn using Tanner L-Edit software, to create multilayer two-dimensional (2-D) layouts. MEMSPRO software was then used to generate 3-D solid models, based upon the 2-D layouts. The 3-D solid models were then refined using Pro-Engineer software, by rounding outside corners and filleting inside corners, to more closely match an actual micropart that is fabricated by the MUMPs fabrication process. Finite element analysis (FEA) was then performed on the refined solid models, to evaluate the stress of a proposed design based upon deflections specified on the model. FEA was performed using Visual Nastran and Pro Mechanica Software.

\section{B. Microgripper Operation}

The operation of the microgripper while it performs its four functions, is now described. The description provides the step-to-step operation, and specifies the operational deflections of the microgripper. In addition, a few of the forces involved in performing the four functions have been estimated, and are included in the description for clarity. The force estimates are based upon on the observed deflections, the geometry of the microgripper and the micropart, and on Young's modulus for polysilicon.

1) Grasping a Micropart: In order to grasp a micropart, the microgripper tips are pushed against the interface feature of the micropart. Since the micropart is tethered to the substrate, a reaction force is developed on the tips, that causes them to open up. Fig. 6(a) illustrates the geometry of the microgripper tips and Fig. 6(b) illustrates the geometry of the interface feature plug. To perform the grasp, the tips are aligned with the plug, and the microgripper is commanded in the $x$-direction, as shown in Fig. 2(b) and Fig. 6(b). Upon contact, the insertion 


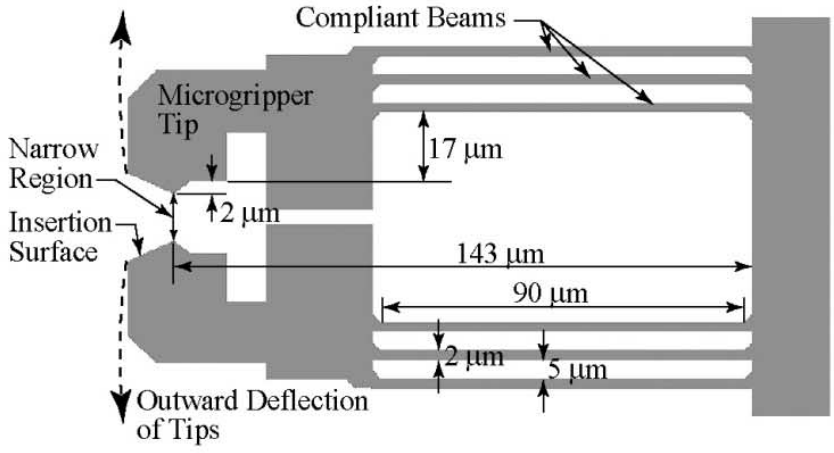

(a)

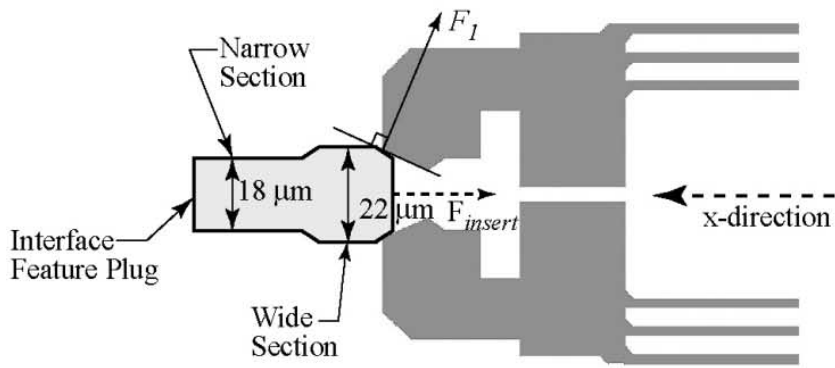

(b)

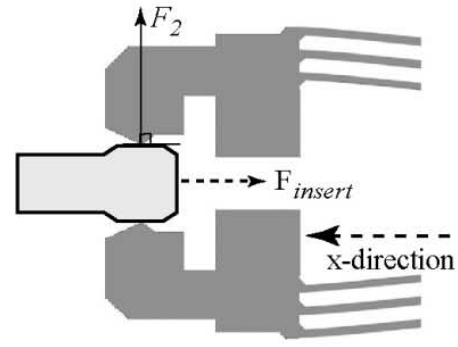

(c)

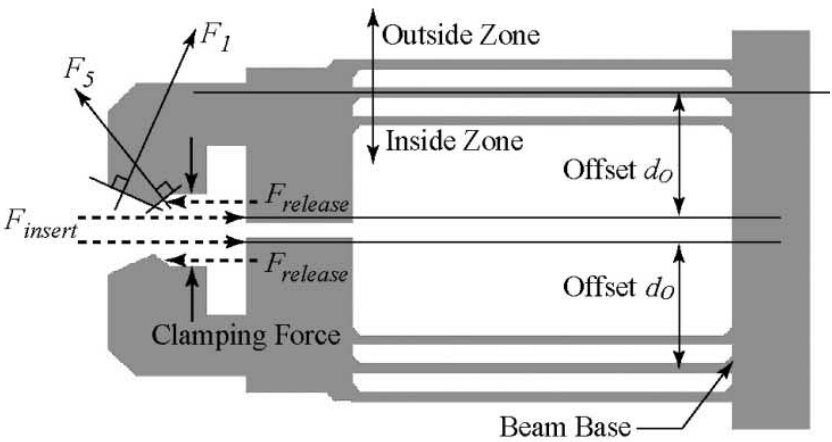

(e)

Fig. 6. Operation of microgripper tips. (a) Compliant microgripper tip profile (b) alignment with interface feature; (c) partial insertion; (d) full grasp; and (e) insertion force for self-tightening condition, and release force.

force $F_{\text {insert }}$, is developed between the tips and the plug. As the tips are pushed further against the $p l u g$, force $F_{1}$ is exerted upon the insertion surface of each tip, causing each tip to deflect outwards. To complete the grasp, the narrow region between the microgripper tips, must pass over and clear the wide section of the plug. In the rest position the narrow region between the tips is $14 \mu \mathrm{m}$ and the wide section of the plug is $22 \mu \mathrm{m}$. As the wide section of the plug passes through the narrow region between the tips, force $F_{2}$ deflects each tip by $4 \mu \mathrm{m}$, as shown in

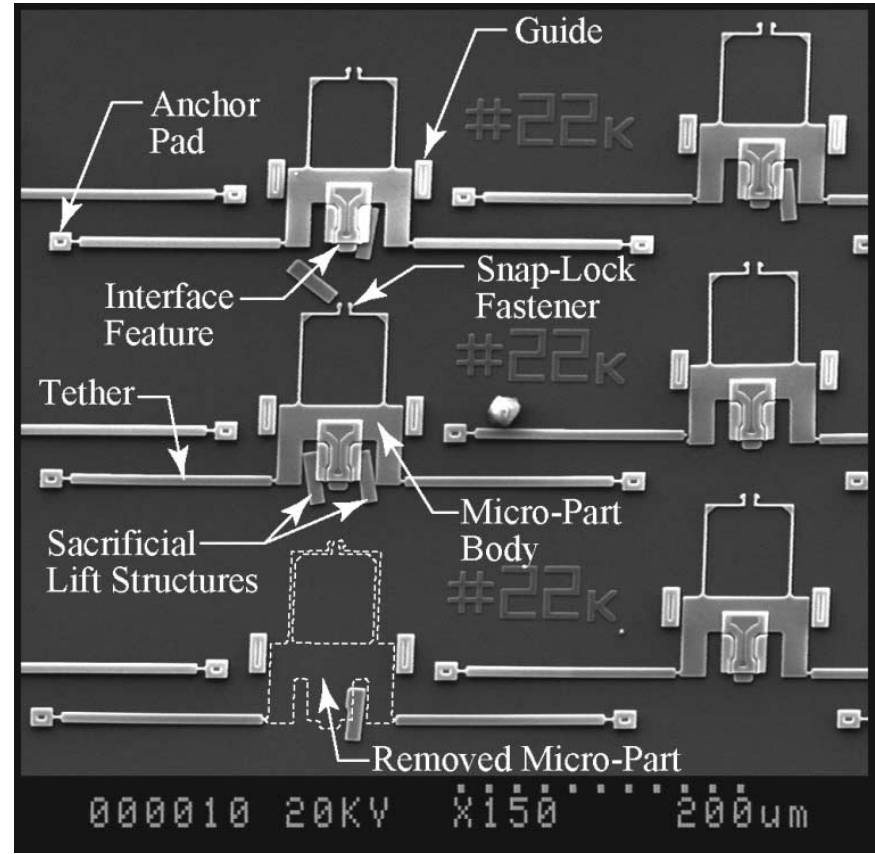

Fig. 7. Microparts tethered to substrate.

Fig. 6(c). Force $F_{2}$ is estimated to be $35 \mu \mathrm{N}$. Next, the wide section of the plug passes into the wide region between the tips, as shown in Fig. 6(d). In this position, the plug is fully grasped, and each tip is deflected by $2 \mu \mathrm{m}$, resulting in force $F_{3}$ being exerted on the tips. Force $F_{3}$ (estimated to be $17 \mu \mathrm{N}$ ) is the static 'holding' force that keeps the micropart securely within the microgripper.

2) Removing a Micropart by Breaking Tethers: After fully grasping the interface feature plug, the next step is to free the micropart from the substrate by breaking the tethers that secure it. Fig. 7 illustrates microparts that are tethered to the substrate of the chip. To break the tethers, the microgripper is commanded to translate further along in the $x$-direction. The $x$-translation causes the push surface of the gripper tips to "push" against the plug, which generates the removal force $F_{4 \text { (removal) }}$ on each gripper tip, as shown in Fig. 6(d). Force $F_{4 \text { (removal) }}$ increases in magnitude as the microgripper is translated in the $x$-direction, and after 9 to $11 \mu \mathrm{m}$ of translation beyond the initial grasp position, the first tether breaks. At 17 to $19 \mu \mathrm{m}$ beyond the initial grasp position, the second tether breaks. The total force exerted on the micropart required to break the first tether is estimated to be at least $120 \mu \mathrm{N}$. After breaking both tethers, the micropart is free from the substrate, while still in the grasp of the microgripper. The design of the tethers and details of the break away are described in Section V-B.

3) Joining a Micropart to Another Micropart: The process of joining a micropart is described in Section V-C. During this process the snap-lock feature is inserted into another micropart, which generates a joining force that is transferred to the microgripper as force $F_{4(\text { joining) }}$. Force $F_{4 \text { (joining) }}$ acts at the same point on the microgripper tip, and in the same direction as force $F_{4 \text { (removal). }}$

4) Releasing a Micropart: After a micropart is joined to another micropart, it becomes fixed to the substrate. The microgripper tips are then commanded to translate away from the in- 
terface feature plug, in the- $x$-direction. This motion causes force $F_{\text {(release) }}$ to be generated between the plug and tips, as shown in Fig. 6(e). Note that force $F_{\text {(release) }}$ can only arise if the microgripper is pulled away from a fixed micropart. The component of force $F_{\text {(release) }}$ acting on the microgripper tips is force $F_{5}$, and causes the tips to deflect outwards. When the tips deflect outward by $4 \mu \mathrm{m}$, they are able to clear the wide section of the plug, and therefore the plug slips out of the tips, which causes the microgripper to release the micropart.

\section{Compliant Design}

Most micromechanisms fabricated by surface micromachining rely on compliant mechanical elements to allow for motion. These elements are able to elastically deform due to an external force exerted upon them. A set of parallel, polysilicon "compliant beams," as shown in Fig. 4 and Fig. 6(a), allow the microgripper tips to deflect outwards. Since three parallel beams are used, the tips remain approximately parallel to each other during their outward deflection. The three beams are 90 $\mu \mathrm{m}$ long, have a cross section of $2 \times 2 \mu \mathrm{m}$, and are spaced 5 $\mu \mathrm{m}$ apart.

The compliant beams are designed to meet two requirements while the microgripper performs the four functions. Firstly, the maximum principal stress in the beams must be less than $25 \%$ of the ultimate stress and secondly, buckling of the beams must be prevented. Addressing the first design requirement, the maximum deflection of the beams occurs during the grasp or release operations. This corresponds to a $4 \mu \mathrm{m}$ outward deflection of the tips (force $F_{2}$ ), as the wide section of the plug passes through the narrow region between the tips, as shown in Fig. 6(c). Using FEA, the beams have been designed such that this deflection results in a maximum stress of approximately $480 \mathrm{MPa}$ in the beams. For the second requirement, the greatest contributing factor for buckling is force $F_{4}$. The maximum magnitude of force $F_{4}$ occurs during the micropart removal operation, during the breaking of the tethers. Based upon the observed tether deflection during the break process, it is estimated that force $F_{4 \text { (removal) }}$ (exerted on each gripper tip) is at least $60 \mu \mathrm{N}$. For the microgripper design of Fig. 6, out-of-plane buckling will occur on the inner most beam when force $F_{4}$ (exerted on a gripper tip) exceeds $120 \mu \mathrm{N}$. Therefore, no buckling of the compliant beams occurs during micropart grasping, removal or joining conditions.

The design of the compliant beams is a compromise between good flexibility for the outward deflection of the grasping tips, and high stiffness to prevent buckling during micropart removal. To decrease the maximum stress within the beams for a given outward deflection, they could be made longer. To increase the stiffness of the beams, and thereby increase the load required for buckling, the beams could be made shorter, thicker, or the offset distance, $d_{o}$, could be decreased. It was found that by increasing the number of parallel beams, the stiffness could be increased, while the maximum stress within the beams remained the same. This approach led to the three beam design of the compliant microgripper.

\section{Self-Tighten Feature Design}

The self-tightening feature of the microgripper gives it the ability to grasp a micropart with a force proportional to the insertion force $F_{\text {insert }}$. The self-tightening concept is illustrated in Fig. 6(e). The dashed arrows pointing toward the right illustrate the insertion force exerted on the push surface of the tips during the micropart removal operation. The line of action of this force is offset from the compliant beam base by distance $d_{o}$. This creates a moment about the beam base, which causes the gripper tips to deflect inwards, which contributes to the force exerted upon the wide section of the interface feature. This extra inward "clamping force," which is in addition to static force $F_{3}$, is proportional to force $F_{4}$. In other words, as force $F_{4}$ increases, the inward clamping force exerted by the tips increases, and hence the term "self-tightening".

A general observation can be made about the self-tightening design. Any force applied anywhere on the microgripper tip, which has a line of action directed toward the "outside zone" of the compliant beams, as shown in Fig. 6(e), will cause the microgripper tip to open outward. Conversely, any force applied anywhere on the microgripper tip, which has a line of action directed toward the "inside zone" of the compliant beams, will cause the microgripper tip to close inward.

\section{E. Passive Microgripper Operational Criteria}

There are two additional criteria that must be emphasized, regarding the operation of the passive microgripper. These two criteria must be met, otherwise the passive microgripper will not function properly.

The first criterion is that the target object (i.e., micropart) must be restrained during the grasping operation. When the microgripper tips are pushed against the target object (i.e., interface feature), the object must be sufficiently restrained so that the reaction force $F_{\text {insert }}$, can be generated. All the microparts used in this work, such as those shown in Fig. 7, are attached to the chip substrate by tethers, and are therefore adequately restrained. A target object could also be restrained by stiction, or by contact with another object, as long as the restraint is sufficient to generate a reaction force $F_{\text {insert }}$ large enough to open the tips. For the microgripper design of Fig. 6, it is estimated that the restraint force required to restrain a micropart, so that it may be grasped, must be approximately $30 \mu \mathrm{N}$ in opposition to force $F_{\text {insert }}$. If the target object is an unrestrained microobject or is insufficiently restrained, it will be pushed by the microgripper instead of being grasped.

The second criterion is that a grasped object must be restrained in order for the passive microgripper to release it. In other words, a micropart must be restrained by, or joined to, some other object before it can be released. This concept is illustrated by observing force $F_{\text {(release) }}$, in Fig. 6(e). The interface feature exerts force $F_{5}$ upon the microgripper tips, while it is being pulled out of the tips. Force $F_{5}$ can only arise if the interface feature does not translate with respect to the microgripper tips, while they are pulled away from it. For the microgripper design of Fig. 6, it is estimated that the restraint force required to hold a micropart, so that it may be released, must be approximately $70 \mu \mathrm{N}$ in opposition to force $F_{\text {(release) }}$. 


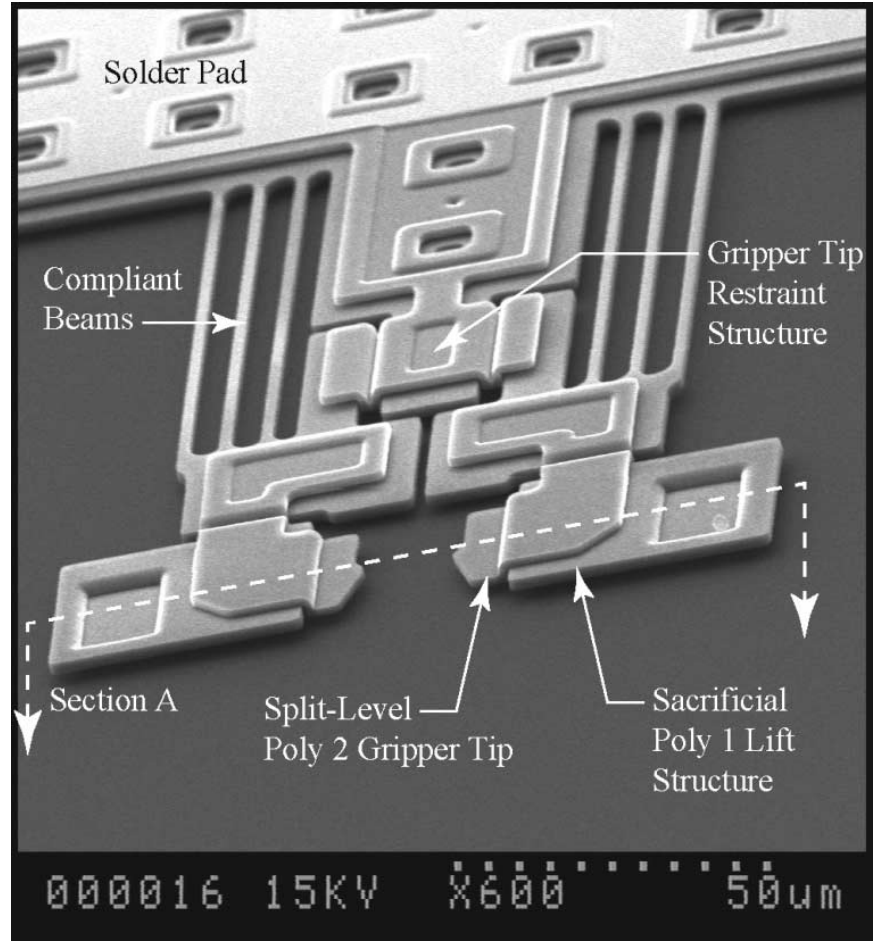

Fig. 8. Image of split-level microgripper tip.

\section{F. 3-D Interlock Design of Microgripper}

The 3-D interlock feature provides out-of-plane restraint for the micropart, and allows the microgripper to secure the micropart in 6 DOF. The interlock is created in part by the geometry of the microgripper tips, and in part by the geometry of the interface feature. Fig. 6(d) illustrated a 2-D outline of the microgripper and the interface feature of the micropart. The interface feature is clearly well restrained in the 2-D plane, however, the diagram does not show how the micropart is restrained in the out-of-plane direction, which can be represented as normal to the page.

In order to provide out-of-plane restraint, the interface feature and the microgripper tip are designed to have an interlocking 3-D structure. This design was a challenging task, since the MUMPs process allows for only two removable structural layers of material, which are deposited conformally. However, by making use of 'sacrificial lift structures', the microgripper tips and the interface feature can have their geometry 'shifted' out-of-plane to allow for 3-D interlock to occur between them.

The out-of-plane geometrical shift that is created on the microgripper tip can be observed in Fig. 8 and Fig. 9. Fig. 8 shows an SEM image of an isometric view of the microgripper tips, while the microgripper is still attached to the substrate. The interlock feature of the microgripper is achieved by designing the gripper tips to have a "split-level." Note that the tips are formed entirely of poly 2 , yet they occupy two different levels. This was achieved by depositing a 'sacrificial lift structure' of poly 1, below the outer edge of the poly 2 tips. Fig. 9 illustrates the geometry corresponding to cross-section A, from Fig. 8. Fig. 9(a) illustrates the microgripper tips before the oxide release, and Fig. 9(b) illustrates them after the oxide release. Note that tips are completely free of the sacrificial lift structure, which is only

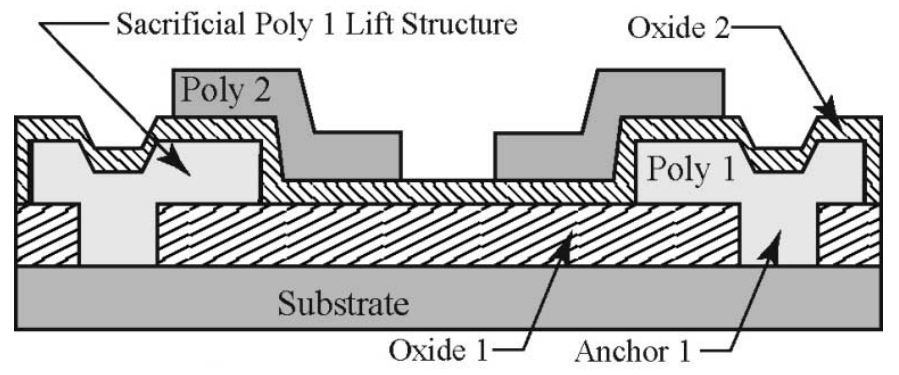

(a)

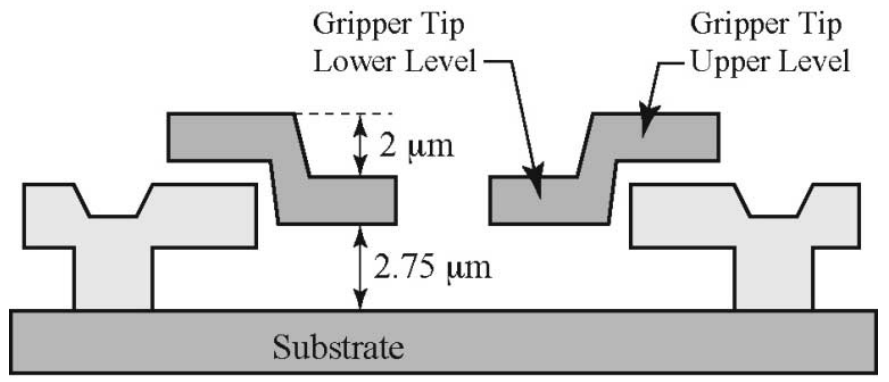

(b)

Fig. 9. Cross-section A of microgripper tip. (a) Before oxide release and (b) after oxide release.

used to "shift" the shape of the tips out-of-plane. Section IV-A. will describe the complete 3-D interlock design, after the interface feature of the microparts is introduced and explained.

\section{Micropart DESIGN}

The purpose of the microparts used in this work is to validate the microassembly process. As such, the microparts shown in Figs. 1, 7, 10, and 12 to 16, have no function other than to demonstrate the three modular design features used for this microassembly system. The modular features are illustrated in Fig. 7. First, each micropart is equipped with an interface feature that is matched to the geometry of the microgripper tips. Second, each micropart is equipped with two tethers that secure it to the substrate. Third, each micropart is equipped with a joint system (snap-lock fastener), to allow it to be joined to other microparts. These features can be considered modular, since they are independent of the shape of the micropart, and function independently of each other.

The tether design and the snap lock joint design are based on deflection and FEA of stress. The design approach is similar to the method used for the microgripper design, and used the same software tools.

\section{A. Interface Feature Design}

Each micropart is equipped with an interface feature, to allow the microgripper to grasp it. The interface feature is a two layer design consisting of poly 1 and poly 2 . Fig. 10 shows an isometric view of the interface feature. Fig. 11 illustrates the geometry corresponding to cross-section B, of Fig. 10 . Fig. 11(a) illustrates the interface feature before the oxide release, and Fig. 11(b) illustrates it after the oxide release. The "central plug" of the interface feature, under the poly 2 layer has a geometry similar to that shown in Fig. 6(b). The plug is 


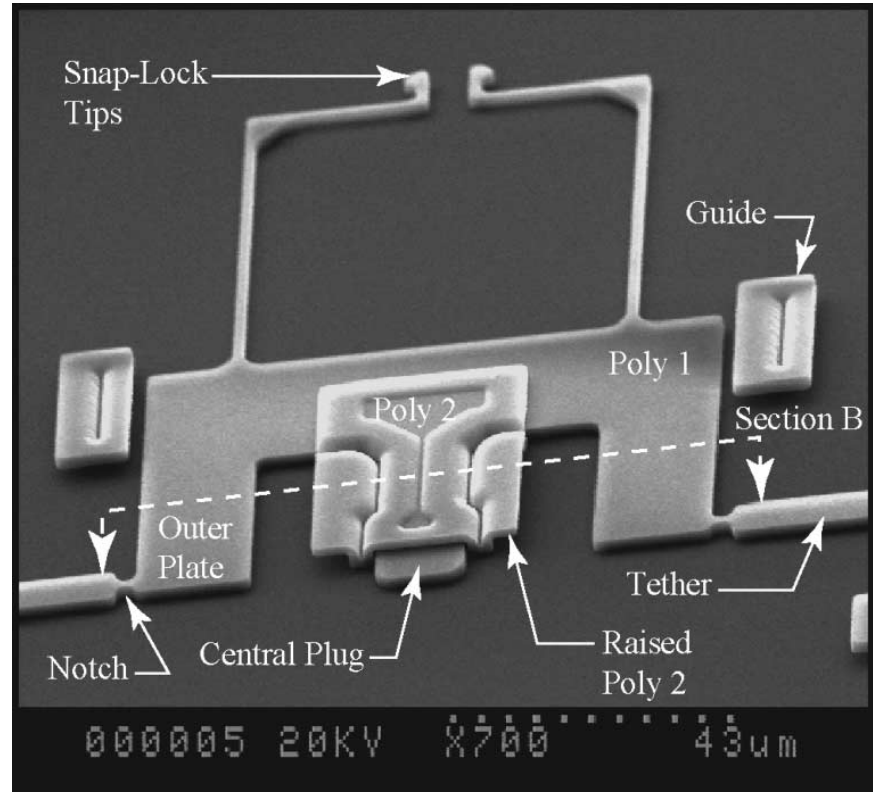

Fig. 10. Image of interface feature.
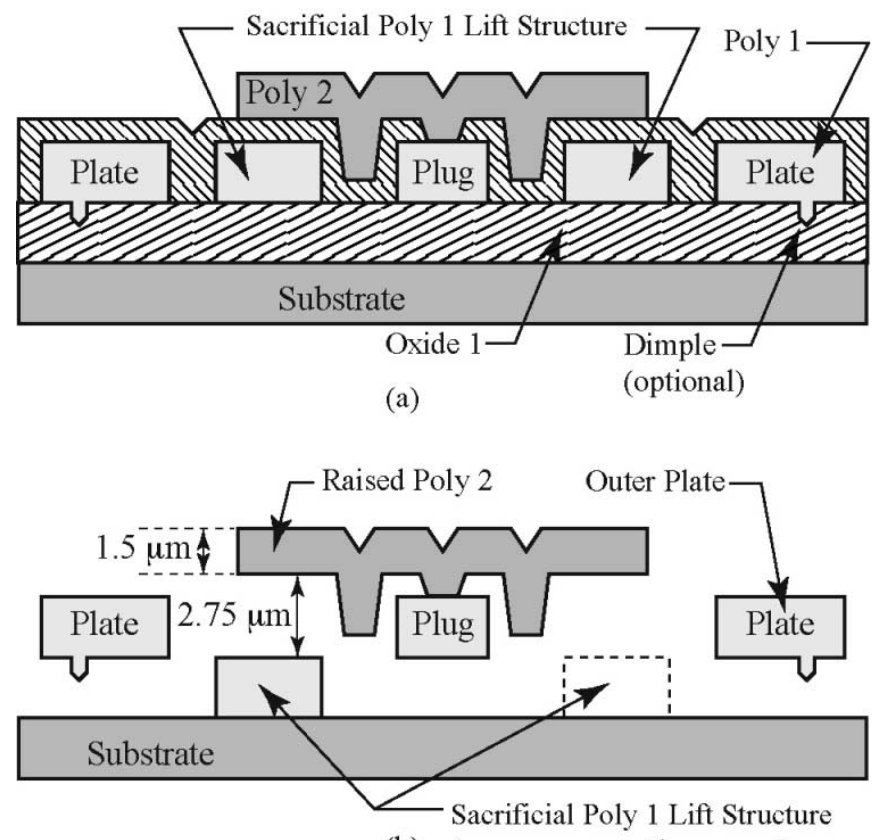

(b) (may or may not be present)

Fig. 11. Cross-section B of interface feature on micropart. (a) Before oxide release and (b) after oxide release.

used to secure the micropart within the microgripper, along the plane of the micropart.

The interface feature also forms the second half of the 3-D interlock system. The purpose of the poly 2 layer is to provide the interlock. Note the "raised poly 2" structure in Fig. 10. Normally, the poly 2 layer would dip down toward the substrate in this region, since the poly 2 deposition is conformal to the underlying layers. However, by depositing a "sacrificial lift structure" of poly 1 , under the poly 2 layer, the 'raised' structure is created. The sacrificial lift structure, as shown in Fig. 7, is not attached to the substrate. As a result, after the oxide release, the sacrificial lift structure either falls down to the substrate, or is washed

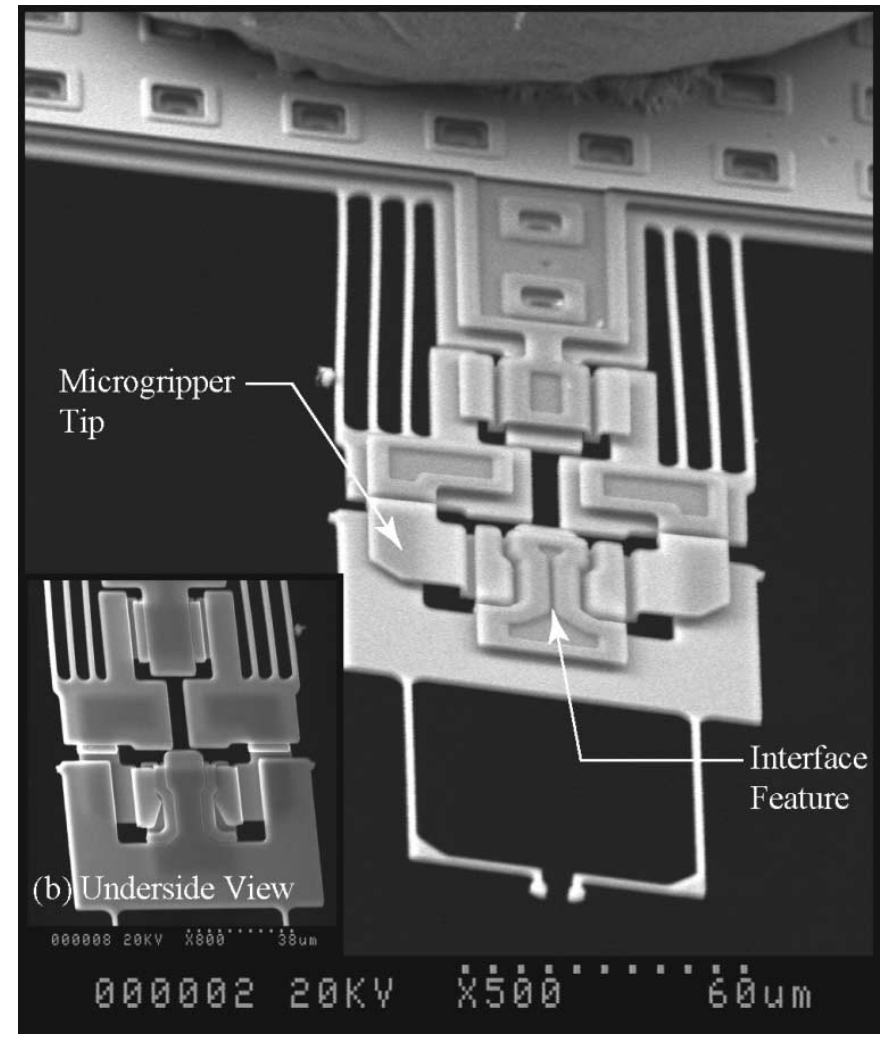

Fig. 12. Microgripper grasping the interface feature of a micropart.

away during the rinse, allowing at least $2.75 \mu \mathrm{m}$ of clearance under the raised poly 2, as illustrated in Fig. 11(b).

Examination of the cross-section of the microgripper tips of Fig. 9(b) and the cross-section of the interface feature of Fig. 11(b), allows the 3-D interlock system to be understood. When the microgripper tips are inserted into the interface feature, the "lower level" of the gripper tips pass under the raised poly 2, while the "upper level" of the gripper tips pass over the "outer plate" of poly 1 . This allows for restraint in the out-of-plane direction, in addition to the in-plane restraint described in Section IV-B. Fig. 12 shows an SEM image of the microgripper grasping a micropart. An underside view of the grasp is shown in Fig. 12(b).

\section{B. Tether System}

Each micropart is secured to the substrate via tethers. The tethers serve three purposes. First, they secure the microparts to the substrate so that the microparts do not move during transportation of the chips, after the oxide release process. Second, they must restrain the microparts sufficiently, so that the passive microgripper is able to grasp the microparts. Third, the tethers must break at predefined locations after being grasped by the microgripper, during the micropart removal procedure.

1) Tether Design: Each micropart is held by two tethers, which are arranged symmetrically about the interface feature, as shown in Fig. 7 and in Fig. 13. The tethers are made of poly 1 and have a narrow "notch" at each end. One end of the tether is attached to the anchor pad, which is fixed to the substrate. This end of the tether has a "flexible notch" that is designed to be flexible. The other end of the tether is attached to the mi- 


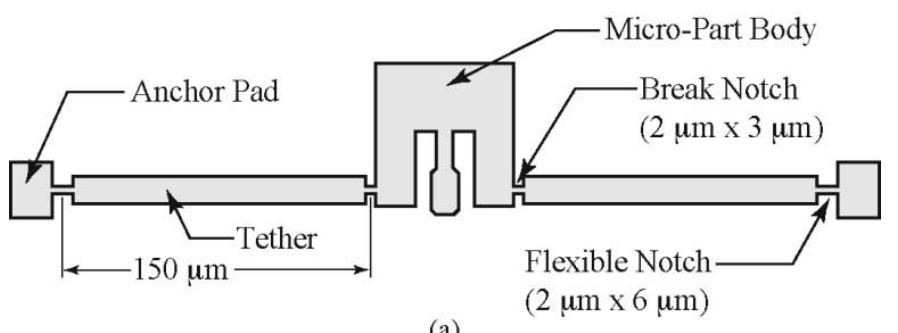

(a)

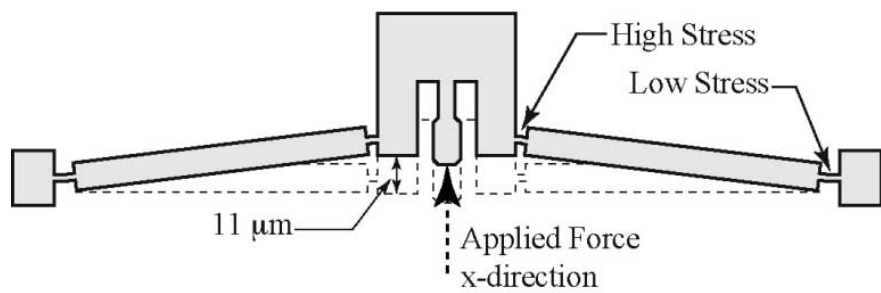

(b)

Fig. 13. Tether design. (a) 2-D outline of tether design and (b) deflection-induced stress on tether notches.

cropart. This end of the tether has a "break notch" that is designed to be strong enough during the grasping operation, but will rupture during the removal operation. Proposed tether designs were modeled using software. A 3-D solid model of the micropart shown in Fig. 13 was created, and the model was then refined by "rounding" the notches to more closely approximate the actual MUMPs fabrication process. By deflecting the micropart in the $x$-direction as shown in Fig. 13(b), the stress in both notches could be estimated, for any given notch geometry. A design parameter that complicated the tether design, was that the minimum allowable cross section for the tether "notch" was $2 \times 2 \mu \mathrm{m}$, due to the MUMPs design rules. Therefore, a certain minimum amount of deflection is required to break a tether notch. By increasing the length of the tether, the stress at the notches can be increased, however this results in more space between adjacent microparts.

2) Grasping a Tethered Micropart: Fig. 14 shows a sequence of video images captured from the microscope system, illustrating the grasping operation. The micropart shown in Fig. 14 is the same one that was located in Fig. 7, in the dashed region labeled 'removed micropart'.

Fig. 14(a) shows the microgripper tips $20 \mu \mathrm{m}$ above the target interface feature. The field of view of the images is $320 \times 240 \mu \mathrm{m}$, and the depth of focus is $1.5 \mu \mathrm{m}$, therefore, all objects closer to, or further from the focal plane appear out of focus. Fig. 14(b) shows the initial stage of the insertion of the tips into the interface feature. Note that the upper level of the tips is above the outer plates of the interface feature, while the lower level of the tips is under the raised poly 2. During the insertion process, various forces, as described in Section IV-B-1, are exerted upon the micropart. Force $F_{\text {insert }}$ causes the micropart to translate in the $x$-direction up to $4 \mu \mathrm{m}$, and causes an estimated stress in the tether break notch of 1 $\mathrm{GPa}$. However, this is not enough stress to rupture the notch. Fig. 14(c) shows the completed grasp. Note that although the microgripper has fully grasped the micropart, the tethers

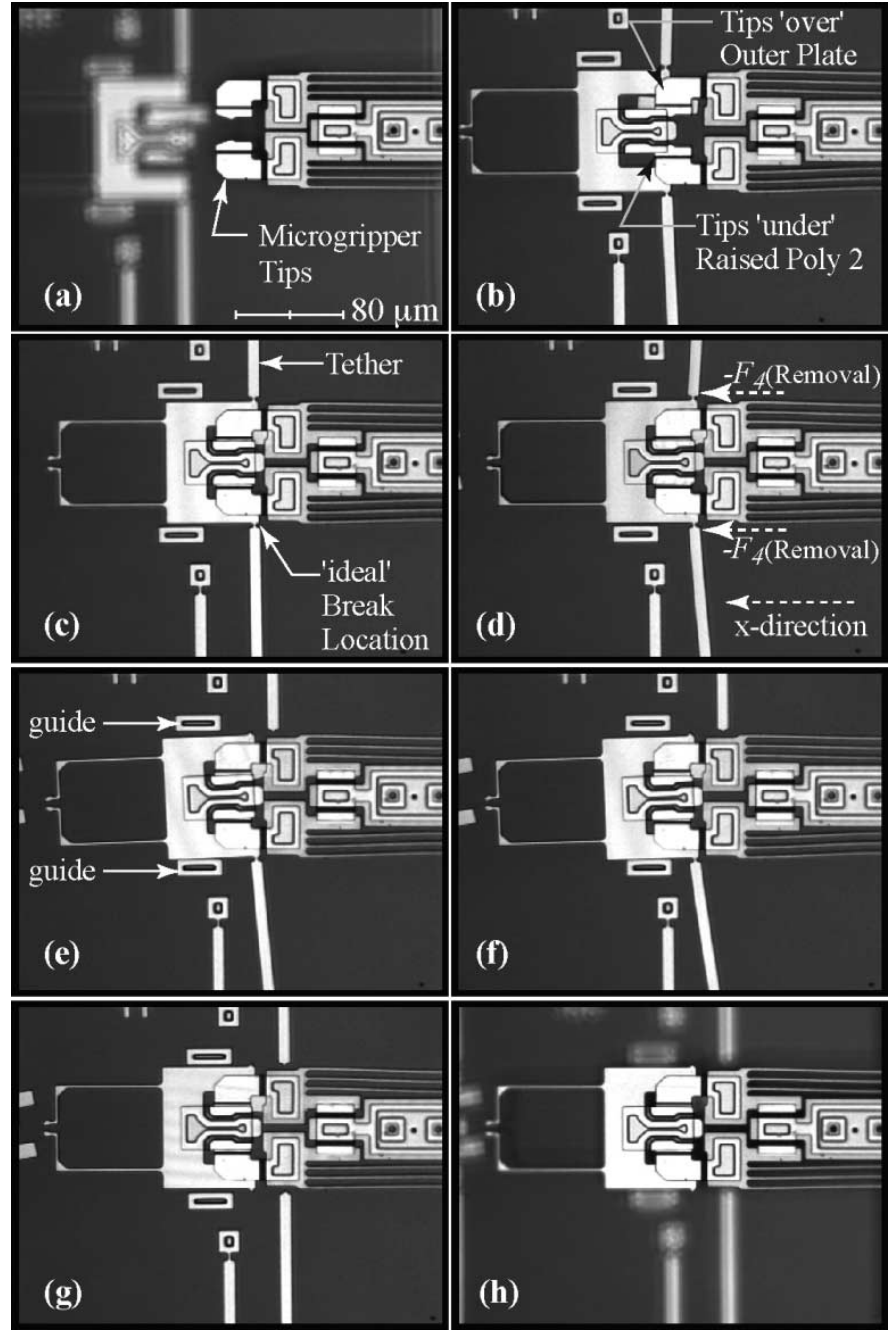

Fig. 14. Grasping a tethered micropart.

remain intact. They are able to restrain the micropart during the grasping operation, without being damaged.

3) Breaking the Tethers to Release Micropart: In order to break the tethers, the microgripper is translated along the $x$-direction while it grasps the micropart. Fig. 14(d) shows the tethers at maximum deflection, just before one of the tethers ruptures. In this configuration, each tip is exerting the removal force, $-F_{4}$, upon the interface feature, and the micropart is deflected by 9 to $11 \mu \mathrm{m}$ from its initial position. This causes an estimated stress of $3 \mathrm{GPa}$ on the break notch of the tethers, which is sufficient to break either tether. Fig. 14(e) shows the configuration just after the upper tether has ruptured. In order to break the remaining tether, the microgripper must be commanded further along the $x$-direction. However, it is important to note that the micropart is no longer held by two tethers. Therefore, the stress distribution created in the remaining tether, due to further $x$-translation of the micropart, will be different from the stress distribution when both tethers were attached. Since the upper tether has ruptured, the micropart will tend to rotate about the anchor pad of the lower tether. This is undesirable, since such a rotation would exert a maximum bending stress at the flexible notch, instead of at the break notch. In order to exert the maximum bending 


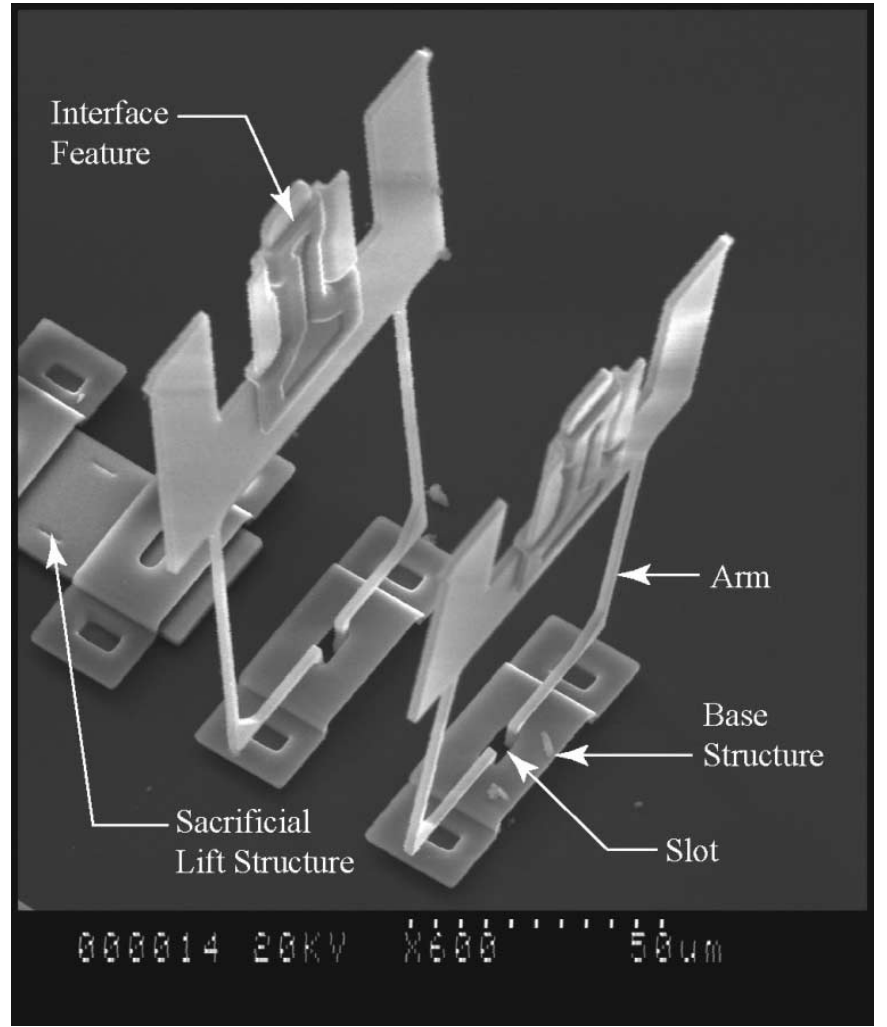

Fig. 15. Microparts joined to perpendicular to base structure.

stress at the break notch, the micropart body must be prevented from rotating while it translates along the $x$-direction. This is achieved with two "guides" labeled in Fig. 10 and Fig. 14(e). The guides ensure that the micropart is oriented such that it remains approximately perpendicular to the remaining tether during its $\mathrm{x}$-translation. This ensures that the maximum stress will occur at the break notch. Fig. 14(f) shows the configuration just before the lower tether ruptures, after the micropart has translated 17 to $19 \mu \mathrm{m}$ from its initial position. Note that the micropart is sliding against the lower guide. Fig. 14(g) shows the configuration just after the lower tether has ruptured, thereby freeing the micropart from the substrate. The microgripper is now commanded up and away from the substrate, while it is grasping the micropart, as shown in Fig. 14(h). A video movie of the grasping, and tether rupture procedure is available online at [18].

\section{Snap-Lock Fastener System}

The system used for creating joints between two microparts is named "snap-lock microassembly" [19]. The system works as follows: one micropart has compliant snap-lock "plug tips," that are press-fit into a mating "slot" in the receiving micropart. The receiving micropart is anchored to the substrate of the chip and is named the "base structure." Fig. 15 shows an SEM image of two microparts that have been joined to base structure microparts.

The plug tip and slot geometries of the snap-lock assembly system vary depending on the application. Fig. 16 illustrates the plug tip and slot geometries used for the microparts and base

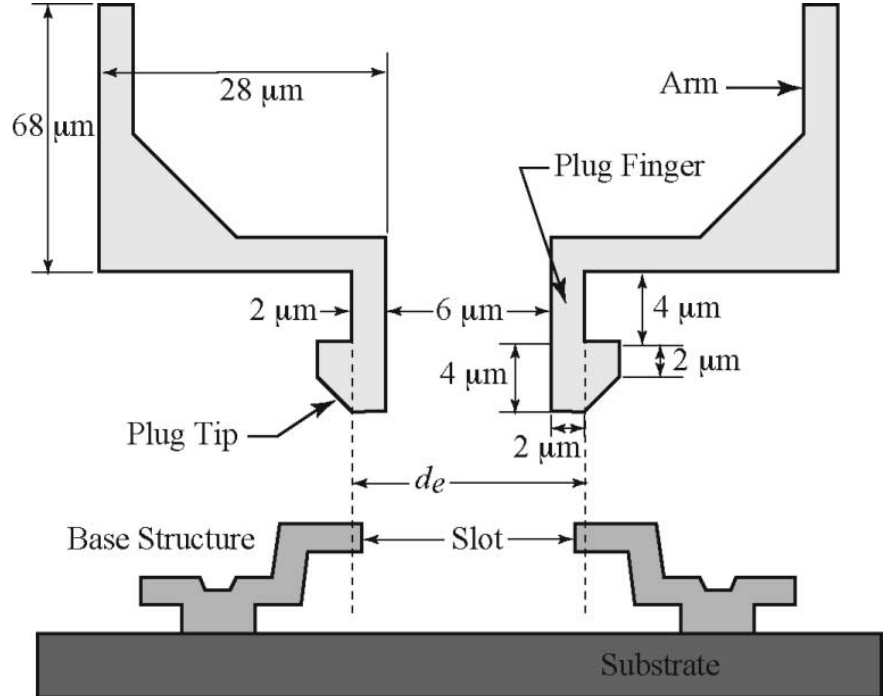

(a)

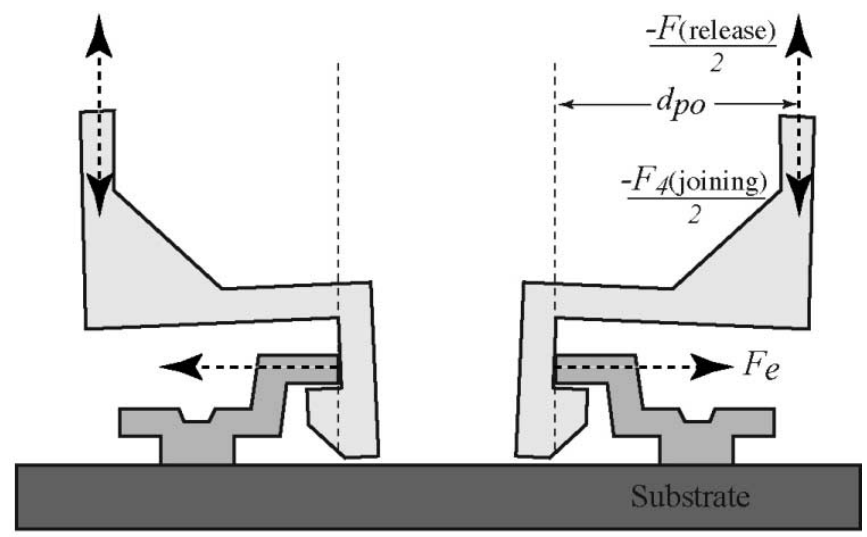

(b)

Fig. 16. Snap-lock plug tip and slot geometry. (a) Plug geometry and base structure cross section and (b) plug inserted into slot.

structure of Fig. 15. The snap-lock joint is created by an interference fit, between the "plug fingers" and the walls of the slot. The distance $d_{e}$, measured from the outside of the two plug fingers, is $10 \mu \mathrm{m}$, while the slot opening is $9 \mu \mathrm{m}$. This results in a $1 \mu \mathrm{m}$ interference, whereby the "arms" of the micropart are elastically deformed and exert an outward force, $F_{e}$ on the slot, as shown in Fig. 16(b). Based on FEA models, it is estimated that $F_{e}$ is $1 \mu \mathrm{N}$ for the microparts of Fig. 15. This force helps to keep the microparts rigidly in position, after they have been inserted into the base structure. Note that due to "rounding effects" of the MUMPs fabrication process, the plug tips shown in Fig. 16(a) become rounded and are able to fit into the slot.

It can be observed from Fig. 16(a) that the snap-lock plug tip is $4 \mu \mathrm{m}$ high. Therefore, the clearance under the slot of the base structure must be greater than $4 \mu \mathrm{m}$, otherwise the plug tip will not be able to form a snap-lock joint. Using a removable sacrificial lift structure of poly 1, as shown in Fig. 15, this clearance can be increased to $4.75 \mu \mathrm{m}$ [19].

In order to create a joint, the microgripper holding the micropart, as shown in Fig. 12, is oriented such that it is perpendicular to the substrate, as shown in Fig. 2(c). The microscope is 


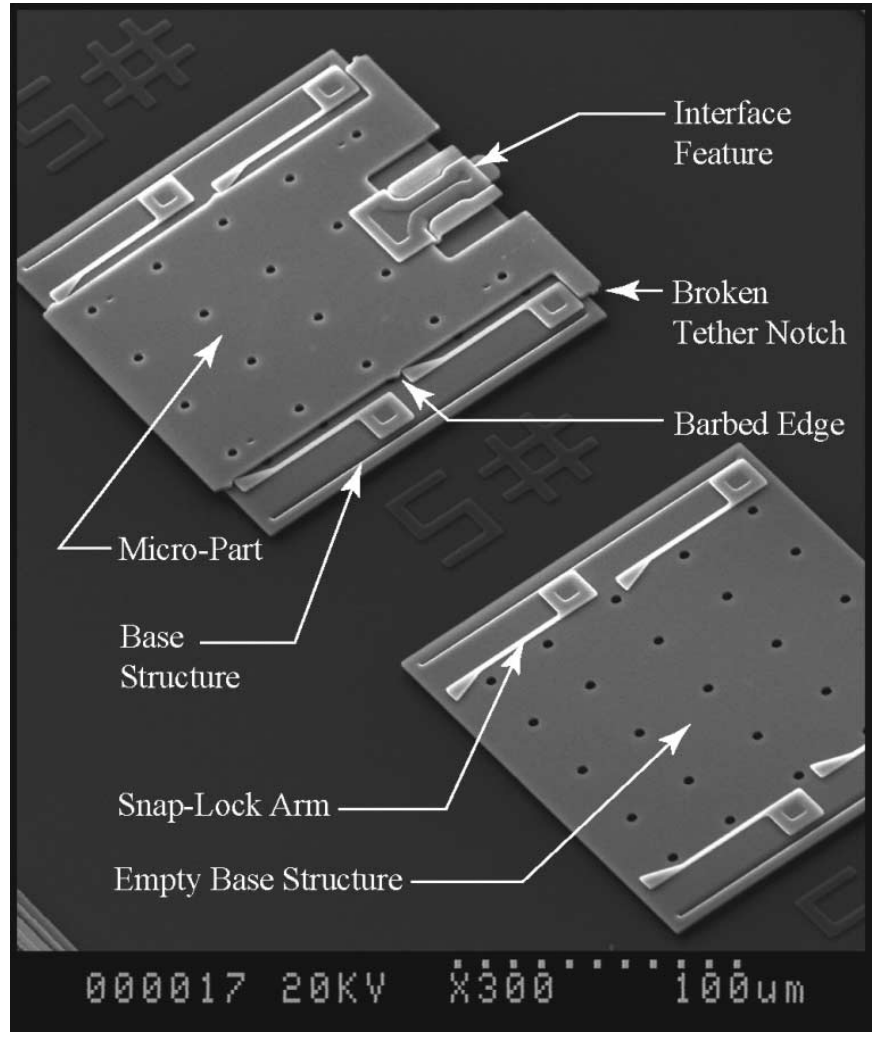

Fig. 17. Micropart joined in-plane with base structure.

brought into focus with the snap-lock plug tips of the micropart, and the plug tips are aligned with the slot in the base structure. During insertion, each plug tip is deflected by a maximum of $2.5 \mu \mathrm{m}$ as it passes through the slot.

Releasing the micropart from the grasp of the microgripper is straightforward. After the snap-lock joint shown in Fig. 16(b) has been achieved, the microgripper is commanded in the $z$-direction (perpendicular to, and away from the substrate). This $z$-translation exerts force $-F_{\text {(release) }}$ on both "arms" of the micropart. The force applied to each arm (one half of force $\left.-F_{\text {(release) }}\right)$ is offset from the slot edge (dashed line) by a distance $d_{p o}$, and generates a moment on the plug finger. For the right plug finger, the moment is in the counter clockwise direction, and for the left plug finger it is clockwise. These moments act to increase the magnitude of force $F_{e}$, and make it impossible for the plug tips to be pulled out of the slot. Therefore, the micropart becomes locked to the substrate, and hence the term "snap-lock" microassembly. When the microgripper is pulled away from this assembled micropart, force $F_{5}$ is generated on the microgripper tips, as shown in Fig. 6(e). This causes the tips of the microgripper to deflect outward by $4 \mu \mathrm{m}$ each, which is enough for the tips to clear the wide section of the interface feature, and therefore release the micropart. A video movie of a typical joining operation is available online at [18].

The snap-lock joints shown in Fig. 15 are approximately $90^{\circ}$ to the plane of the substrate. Using this microassembly system, it is also possible to assemble microparts with snap-lock joints, that are in-plane with the substrate. Fig. 17 illustrates an SEM image of a micropart that is joined in-plane with the substrate,

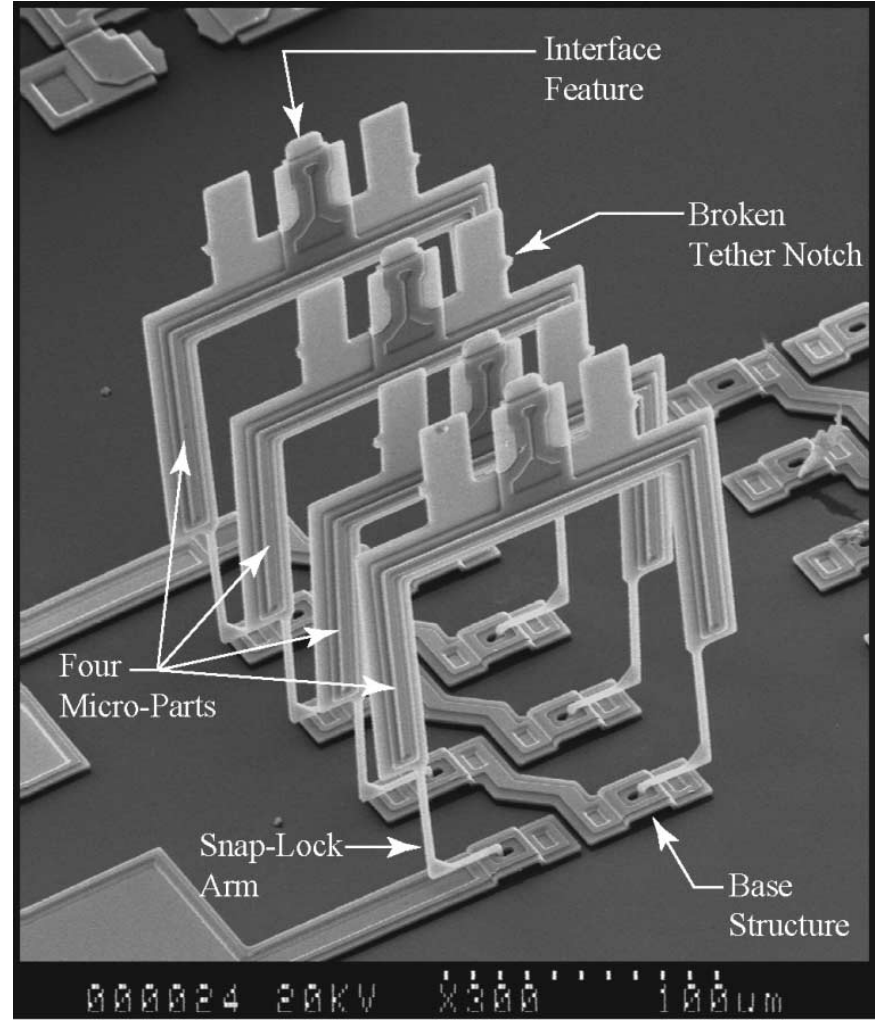

Fig. 18. Microcoil constructed using snap-lock microassembly.

onto a base structure micropart. The micropart is equipped with the required modular features, which are a) an interface feature, b) tethers (only the broken "break notch" is visible), and c) barbed edges to accommodate a snap-lock joint. Note that the compliant snap-lock arms are on the base structure and not on the micropart. The geometry and forces involved in this snap-lock system are different than those described for Fig. 15 and Fig. 16, however, the concept is the same. By inserting the micropart into the base structure, a permanent, mechanical, snap-lock joint is created. When the microgripper is commanded away from the interface feature (in-plane with the interface feature), it releases the micropart, which is fixed to the base structure.

\section{Application of Microassembly}

The described microassembly system has been used for the construction of out-of-plane microcoils [24]. Microcoils can serve as transducers to convert between electromagnetic signals and electrical signals, and could be used in RF (Radio Frequency) microdevices. Fig. 18 shows an SEM of a microcoil constructed from four microparts. The microcoil is $200 \mu \mathrm{m}$ tall and $140 \mu \mathrm{m}$ wide. The microparts used to construct it are $5 \mu \mathrm{m}$ thick and have a pitch to pitch spacing of $50 \mu \mathrm{m}$. Each micropart is equipped with an interface feature, two tethers (only the 'break notches' are visible), and a snap-lock plug. The microparts are initially located on the substrate in rows. Using the passive, compliant microgripper, a micropart is grasped and removed from the substrate. The micropart is then oriented to be perpendicular to the substrate, and the plug tips are lined up with the target slot on the base structure. The 
micropart is then inserted into the base structure and released by the microgripper. The base structure serves to close the loop circuit, between adjacent microparts.

\section{DISCUSSION/CONCLUSION}

A method of fabricating 3-D, out-of-plane microstructures using a passive, compliant microgripper and surface micromachined microparts has been described. A microassembly workstation equipped with a microgripper was used to first grasp the microparts, and then remove them from the substrate of the chip. The microparts were then oriented perpendicular to the chip, and lined up with the base structure microparts. By inserting the snap-lock plug tips of the microparts into the slots of the base structure, joints were created. A few observations are made about this system.

\section{A. Micromanipulation Versus Microassembly}

For general micromanipulation, this passive microgripper is much less versatile than microgrippers that can be actively controlled to open and close their tips. Actively controlled microgrippers are well suited for grasping irregular objects, in dynamic environments. Since this microgripper can only grasp and release objects that are adequately restrained, and that have specific geometries, micromanipulation possibilities are very limited.

In relation to microassembly, however, this microgripper is ideally suited. In the case of this work, the microparts are: 1) of a known size, geometry and have an interface specifically suited for the microgripper. 2) The microparts are attached to the substrate at known locations by the tether system, and are well restrained. 3) The microparts are always joined to other microparts, before they are released. Therefore, given that the passive microgripper presented here can satisfy points 1 ) -3 ), it is well suited for microassembly.

\section{B. Stiction}

Stiction can be both a benefit and a problem for micromanipulators. It can be a benefit during the grasping process as it helps hold the microobject. However, it can be a problem during the process of releasing a microobject. Generally, a microobject can only be released if the force attempting to free it from the microgripper tips is greater than the force of stiction with the tips. This microassembly system enjoys the benefits of stiction during operations like grasping, holding and joining of microparts. However, stiction does not present a problem during the releasing of microparts, since each micropart used in this work is always snap-lock joined to another object before it is released. Stiction is noticeable in this system during "casual" contact between microparts within the grasp of the microgripper, and other microparts. However, these stiction forces are observed to have little effect on the grasp configuration.

\section{Modular Design and Multiple Sources for Microparts}

The microgripper described here is fabricated using the MUMPs surface micromachining process. However, it can be fabricated by any surface micromachining process that includes two structural polysilicon layers and a gold layer. Similarly, the microparts can also be fabricated by any surface micromachining process, however, there is no material restriction. Any surface micromachinable material can be used for the micropart structural layers, as long as the interface feature has the correct geometry, as shown in either Fig. 7 or Fig. 10 and 11. The tether design and the snap-lock design are also geometry based, although using different materials would require new analysis for the rupture stress and joining stress. In terms of designing the base structure used for joining microparts, only the slot with sufficient clearance underneath is required. Therefore, it is proposed that bulk micromachining could be used to etch holes into a silicon substrate to create appropriate slot features. This creates possibilities such as joining surface micromachined microparts, to CMOS chips. The use of a microassembly system allows for many possibilities.

\section{ACKNOWLEDGMENT}

The authors wish to thank the Canadian Microelectronics Corporation $(\mathrm{CMC})$ for granting chip fabrication area.

\section{REFERENCES}

[1] G. A. Singh, D. Horsely, M. Cohn, A. Pisano, and R. Howe, "Batch transfer of microstructures using flip-chip solder bonding," J. Microelectromech. Syst., vol. 8, pp. 27-33, Mar. 1999.

[2] M. M. Maharbiz, R. T. Howe, and K. S. J. Pister, "Batch transfer assembly of micro-components onto surface and SOI MEMS," in Proc. Transducers '99 Conference, Sendai, Japan, June 7-10, 1999.

[3] T. Ebefors, J. Ulfstedt-Mattsson, E. Kälvesten, and G. Stemme, "3D micromachined devices based on polyimide joint technology," in SPIE Symposium on Microelectronics and MEMS, vol. SPIE Vol. 3892, Gold Coast, Queensland, Australia, October 1999, pp. 118-132.

[4] K. F. Harsh, V. M. Bright, and Y. C. Lee, "Solder self-assembly for threedimensional microelectromechanical systems," Sens. Actuators, Phys. A, vol. 77, pp. 237-244, 1999.

[5] J. Zou, J. Chen, C. Liu, and J. E. Schutt-Ainé, "Plastic deformation magnetic assembly (PDMA) of out-of-plane microstructures: technology and application," J. Microelectromech. Syst., vol. 10, pp. 302-309, June 2001.

[6] K. F. Bohringer, K. Goldberg, M. Colm, R. Howe, and A. Pisano, "Parallel microassembly with electrostatic force fields," in Proc. International Conference on Robotics and Automation (ICRA98), Leuven, Belgium, May 1998.

[7] S. R. Burgett, K. S. J. Pister, and R. S. Fearing, "Three dimensional structures made with microfabricated hinges," in Proc. MicroMechanical Systems, ASME Winter Annual Meeting, vol. 40, Anaheim, CA, 1992, pp. 1-11.

[8] A. Friedberger and R. S. Muller, "Improved surface-micromachined hinges for fold-out structures," J. Microelectromech. Syst., vol. 7, pp. 315-319, Sept. 1998

[9] E. Hui, R. T. Howe, and S. M. Rodgers, "Single-step assembly of complex 3-D microstructures," in Proc. IEEE Thirteenth Annual International Conference on Micro Electro Mechanical Systems, Miyazaki, Japan, Jan 2000, pp. 602-607.

[10] E. Shimada, J. A. Thompson, J. Yan, R. Wood, and R. S. Fearing, "Prototyping millirobots using dextrous microassembly and folding," in Proc. ASME IMECE/DSCD, Orlando, Florida, Nov. 5-10, 2000, pp. 933-940.

[11] G. Yang, J. A. Gaines, and B. J. Nelson, "A flexible experimental workcell for efficient and reliable wafer-level 3D microassembly," in Proc. IEEE International Conference on Robotics and Automation (ICRA 2001), Seoul, South Korea, 2001, pp. 133-138.

[12] Zyvex Microgrippers, Micromachined Silicon Structures, Top Down Group.http://www.zyvex.com/Products/Grippers.html [Online]

[13] C. G. Keller and M. Ferrari, "Milli-scale polysilicon structures," in Proc. Solid-State Sensor and Actuator Workshop, Hilton Head, SC, June 1994, pp. 132-137.

[14] Photo Gallery, MEMS Precision Instruments, C. G. Keller.http://www.memspi.com/gallery.html [Online] 
[15] J.T. Feddema and R.W. Simon, "Visual servoing and CAD-driven microassembly," Special Issue on Visual Servoing, IEEE Robotics and Automation Magazine, vol. 5, no. 4, pp. 17-24, Dec. 1998.

[16] C. J. Kim, A. P. Pisano, and R. S. Muller, "Silicon-processed overhanging microgripper," J. Microelectromech. Syst., vol. 1, pp. 31-36, Mar. 1992.

[17] N. Dechev, W. L. Cleghorn, and J. K. Mills, "Microassembly of 3-D MEMS structures utilizing a MEMS microgripper with a robotic manipulator," in Proc. IEEE International Conference on Robotics and Automation (ICRA 2003), Taipei, Taiwan, Sept 14-19, 2003.

[19] N. Dechev, W. L. Cleghorn, and J. K. Mills, "Micro-assembly of microelectromechanical components into 3-D MEMS," Canadian J. Elec. Comput. Eng., vol. 27, no. 1, pp. 7-15, January 2002.

[20] S. J. Ralis, B. Vikramaditya, and B. J. Nelson, "Micropositioning of a weakly calibrated microassembly system using coarse-to-fine visual servoing strategies," IEEE Trans. Electron. Packag. Manufact., vol. 23 , Apr. 2000.

[21] D. Koester, A. Cowen, R. Mahadevan, and B. Hardy, "PolyMUMPs design handbook revision 8.0," in MEMSCAP, MEMS Business Unit (CRONOS) Research Triangle Park, NC, 2001.

[22] W. N. Sharpe and K. Jackson, "Tensile testing of MEMS materials," in Proc. 2000 SEM IX International Congress, Orlando, FL, June 5-8, 2000.

[23] W. N. Sharpe, B. Yuan, R. Vaidyanathan, and R. L. Edwards, "Measurements of Young's modulus, Poisson's ratio, and tensile strength of polysilicon," in Proc. Tenth IEEE International Workshop on Microelectromechanical Systems, Nagoya, Japan, 1997, pp. 424-429.

[24] N. Dechev, W. L. Cleghorn, and J. K. Mills, "Construction of a 3D MEMS microcoil using sequential robotic microassembly operations," in Proceedings ASME International Mechanical Engineering Congress and $R \& D$ Expo 2003, Washington, DC, Nov 15-21, 2003.

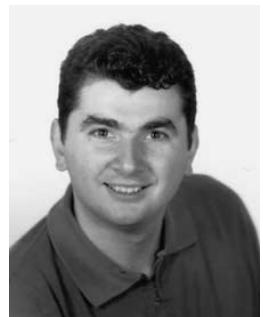

Nikolai Dechev (M'00) received the B.A.Sc. degree in mechanical engineering and the M.A.Sc. degree from the University of Toronto, ON, Canada, in 1996 and 1999 , respectively. He is currently working toward the Ph.D. degree in mechanical engineering at the University of Toronto.

His research interests include mechanisms, robotics, robotic grasping, micromachines and biomechanical design. His M.A.Sc. work involve the development of a "Multiple Finger, Passive Adaptive Grasp Prosthetic Hand", Journal of Mechanism and Machine Theory, vol. 36, no. 10, pp. 1157-1173, 2001. His current research specializes in the application of robotic assembly to MEMS.

Mr. Dechev is a Student Member of the American Society of Mechanical Engineers (ASME).

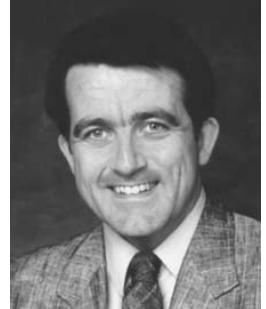

William L. Cleghorn received the B.A.Sc. degree in 1975, the M.A.Sc. degree in 1976 and the Ph.D. degree in 1980, all from the University of Toronto, ON, Canada, Department of Mechanical Engineering.

$\mathrm{He}$ is currently Professor at the same department and his current areas of research include dynamics, vibrations and mechanisms. He has published over 200 journal and conference papers in these areas. He currently holds the Clarice Chalmers Chair of Engineering Design.

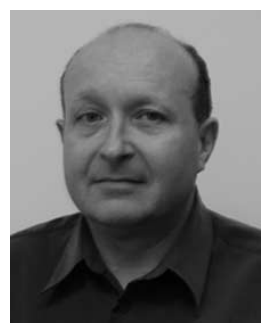

James K. Mills (M'95) received the Bachelor's and Master's degree in electrical engineering in 1980 and 1982, respectively, and the Ph.D. degree in mechanical engineering in 1987 from the University of Toronto, ON, Canada.

$\mathrm{He}$ is currently Professor in Mechanical Engineering, at the University of Toronto and his research interests have encompassed a number of related areas, including: robot control, control of multirobots, control of flexible link robots, design of actuators, localization, development of fixtureless assembly technology, design and control of high-speed machines, development of neural network controllers, etc. He has published over 220 journal and conference papers and supervised over 55 Masters and Ph.D. students an a number of PostDoctoral Fellows and Research Engineers. He has been an Invited Visiting Professor at the Centre for Artificial Intelligence and Robotics in Bangalore, India, in 1997 and The Hong Kong University of Science and Technology in 1995. More recently, he was a Visiting Professor in the Department of Automation and Computer Aided Engineering at the Chinese University of Hong Kong during 2002-2003. 